\title{
Do intrauterine device/intrauterine system users check their threads?
}

\author{
Amanda Davies, ${ }^{1}$ Charlotte Fleming ${ }^{2}$
}

\begin{abstract}
${ }^{1}$ Specialist Registrar in Sexual and Reproductive Health, Aneurin Bevan Health Board Sexual and Reproductive Health, Newport, UK

${ }^{2}$ Consultant in Sexual and Reproductive Health, Aneurin Bevan Health Board - Sexual and Reproductive Health, Newport, UK
\end{abstract}

\section{Correspondence to} Dr Amanda Davies, Aneurin Bevan Health Board - Sexual and Reproductive Health, Llanyrafon House, Llanfrechfa Grange, Torfaen, Cwmbran NP44 8YN, UK daviesac4@cf.ac.uk

Received 8 January 2013 Revised 25 July 2013 Accepted 1 August 2013 Published Online First 25 September 2013
To cite: Davies A, Fleming C. I Fam Plann Reprod Health Care 2014:40:122-125.

\begin{abstract}
Background Expulsion of an intrauterine device (IUD) occurs in about 1 in 20 women and expulsion may not be noticed by the user. Current guidance recommends that users are instructed to check regularly for their threads. This is the first study to explore the reality of how women feel about checking their threads and the details surrounding how frequently checks are done.

Methods One hundred consecutive IUD users were interviewed regarding their type of device, duration of use, frequency of thread checking, prompts for checking and reasons for not checking.
\end{abstract}

Results Only 23\% checked their threads regularly and $51 \%$ had never done so. The most common reason for not checking was forgetting about it.

Conclusions Despite being advised to do so, the majority of users do not check their threads at all and fewer than one-quarter of them check regularly. We propose that advice offered about thread checking should be given less emphasis and suggested more for user reassurance.

\section{INTRODUCTION}

The incidence of copper-bearing intrauterine device (Cu-IUD)/levonorgestrelcontaining intrauterine system (LNG IUS) expulsion quoted in the literature varies widely, but it is generally considered to occur in 1 in 20 women. ${ }^{1}$ Expulsion can occur at any time during the 5-10 years of device use, but is said to be most common in the first 3 months after insertion, and often during menstruation. ${ }^{1}{ }^{2}$ About 1 in 5 expulsions are not noticed by the device user. ${ }^{3}{ }^{4}$ Therefore, approximately $1 \%$ of women will experience an unrecognised expulsion while using the IUD for contraception, and be at risk of pregnancy.

Until 2004, users were recommended to undergo an annual checkup for their IUD, and one reason for this was so that a health professional could check for the presence

\section{Key message points}

Most women do not follow the advice to check their intrauterine device (IUD) threads, and if they did it would generate a large volume of work, probably with little benefit.

- Pregnancy following unnoticed IUD expulsion is uncommon.

- Advice on checking threads should be given less emphasis and only suggested for those at high risk of expulsion or for user reassurance.

of the threads. ${ }^{5}$ Although annual checkups are no longer advised, the Faculty of Sexual \& Reproductive Healthcare (FSRH) recommends that women should be given instruction on how to check for the IUD threads "after each menstruation or at regular intervals. Users should be advised that if they are unable to feel their threads, it may be that the device has been expelled, and alternative contraception should be used until the position of the device is confirmed". ${ }^{2}$

Locally we use a proforma to record the details of an IUD insertion, and there is a section to complete concerning advising women to check threads. The advice we give to women is that checking threads is recommended by the FSRH as quoted above, and written information is also provided.

Anecdotally we felt that many women do not check their threads despite having been advised to do so. We designed this study to investigate this scenario further, and to explore women's reasons for checking their threads or not doing so.

\section{METHODS}

One hundred consecutive $\mathrm{Cu}-\mathrm{IUD} / \mathrm{LNG}$ IUS users seen by the first author 
attending a walk-in sexual health clinic in Aneuran Bevan Health Board in 2010 underwent a structured interview regarding checking their IUD threads. All the interviews were carried out in person by the first author, and consent was obtained in each case. The device users were attending clinic for a variety of reasons, which may or may not have been in connection with their IUD/IUS.

Women were asked what type of device they used, how long they had used it, what bleeding patterns they had, how many times they had checked their threads in the last 12 months, who checked them, reasons for not checking, and what prompted them to check. The women were also asked whether they had been told to check their threads, and explored how comfortable the women were with self-examination.

Women using the LNG IUS for non-contraceptive reasons were excluded from the study, as checking for threads would be less relevant for them. Women whose device was not fitted in the authors' own service were also excluded in order to audit the advice given within this particular service.

\section{RESULTS}

The average duration of use was 3 years and 6 months (range 5 months-17 years). Fifty-five women were LNG IUS users and 45 were Cu-IUD users. The average age of the women in the study was 37 (range $18-57)$ years. As a total of 100 women were interviewed, the number of women also represents the percentage, unless otherwise stated.

\section{Advice on checking}

Eighty-four women could remember being told to check their threads, and 80 understood why they should do so.

\section{Frequency of checking}

Half the users in the authors' service had not checked their threads at all, and only about one-fifth checked them with any regularity. In the last 12 months, 51 women had never checked their threads, nine had done it once, 17 women had checked 2-3 times, nine had checked 4-6 times and only 14 women had checked $>7$ times. Neither age nor duration of IUD use influenced the frequency of thread checks (Tables 1 and 2).

\section{Influences on frequency of checking}

Women's frequency of checking was not influenced by their age, the duration of use of the device or menstrual cycle. $\mathrm{Cu}-\mathrm{IUD}$ users checked slightly more often than LNG IUS users, although this did not reach statistical significance.

Those women who could not remember being advised to check their threads had checked less often than those who could remember, as would be expected. Thirteen of the 16 women who could not
Table 1 Comparison of duration of use with frequency of checking intrauterine device threads

\begin{tabular}{lcllll}
\hline \multirow{5}{*}{ Year } & \multicolumn{5}{l}{ Frequency of checking } \\
\cline { 2 - 6 } & Never & Once & 2-3 times & 4-6 times & >7 times \\
\hline 1 & 9 & 2 & 0 & 3 & 3 \\
2 & 8 & 2 & 3 & 0 & 4 \\
3 & 5 & 0 & 1 & 2 & 0 \\
4 & 6 & 3 & 3 & 0 & 1 \\
5 & 14 & 1 & 8 & 2 & 6 \\
$6+$ & 9 & 1 & 2 & 2 & 0 \\
\hline
\end{tabular}

remember this advice had not checked at all, and the other three had only checked once.

\section{Who checks the threads}

Of those women who had ever checked their threads, $63 \%$ checked themselves, 9\% said their partner checked and $28 \%$ had been checked at a clinic.

\section{Prompts to check}

Gynaecological symptoms (10\%) and visits to the clinic for other reasons (16\%) were the most frequently mentioned prompts, but many women could not say what prompted them to check.

\section{Reasons for not checking}

Of the reasons given, about one-third demonstrated lack of understanding of the reasons for checking or the recommended frequency of checking, one-third appeared to be choosing to forget about it and the final third were not confident about how to feel for the threads. A small number of women knew in other ways that their device was in place, and only $4 \%$ of women admitted to being uncomfortable with selfexamination and stated that this put them off checking.

Table 3 outlines the reasons women gave for not checking their threads, or not checking them more often. Women may have given more than one reason, so the numbers total more than 100 .

\section{DISCUSSION}

It has been reported that one-third of IUD users cannot manage to feel their threads at all, ${ }^{6}$ and the findings of the present study support this figure.

Table 2 Comparison of woman's age with frequency of checking intrauterine device threads

\begin{tabular}{lcllll}
\hline & \multicolumn{6}{l}{ Frequency of checking } \\
\cline { 2 - 6 } Age (years) & Never & Once & 2-3 times & 4-6 times & $>$ 7 times \\
\hline$<20$ & 0 & 0 & 0 & 1 & 0 \\
$21-30$ & 12 & 1 & 7 & 3 & 6 \\
$31-40$ & 23 & 3 & 6 & 2 & 4 \\
$>40$ & 16 & 5 & 4 & 3 & 4 \\
\hline
\end{tabular}


Table 3 Reasons given by women for not checking their intrauterine device threads

\begin{tabular}{lr}
\hline Reason & $\boldsymbol{n}$ \\
\hline I just forget about it & 26 \\
Tried and couldn't & 21 \\
Didn't know I should do more often & 21 \\
I would know if it fell out & 9 \\
I can tell by my periods & 5 \\
I can feel it anyway & 4 \\
I don't like to examine myself & 4 \\
I didn't know what I was feeling for & 4 \\
No one told me why & 3 \\
It is difficult to feel & 3 \\
I didn't think there was any problem & 2 \\
I assume it is there & 2 \\
I only check when I come to clinic & 2 \\
I wasn't told how to & 1 \\
I don't have time & 109 \\
\hline Total reasons & \\
\hline
\end{tabular}

Therefore, if all women followed the currently recommended FSRH advice exactly, then one-third of IUD users would present to their general practitioner or clinic with 'missing threads' to investigate. This would have large workload and cost implications, and would be inconvenient for the patients. Studies looking at the outcomes of investigations into missing threads show that even in those patients in whom the clinician is unable to visualise the threads on speculum examination, between $69 \%$ and $99 \%$ of devices are correctly situated within the uterine cavity on ultrasound examination. ${ }^{78}$

One-third of the reasons given by the IUD users in the present study for not checking their threads were that the women did not know how to check or were unable to feel their threads. This is a similar proportion to those described by Husemeyer 30 years earlier. ${ }^{6}$ If thread-checking remains a priority, then there may be a case for better written information and active teaching for women on how to feel their threads at the time of the IUD fitting.

Randomised controlled trials using the T380 $\mathrm{Cu}^{\circledR}$ IUD report cumulative expulsion rates ranging from $3-6 \%$ at 1 year, $5-7 \%$ at 2 years, $5 \%$ at 3 years and $11 \%$ at 10 years. ${ }^{1}$ There appears to be little difference in expulsion rates between the T380 Cu IUD and the LNG IUS. ${ }^{1}$ It has been shown that a history of previous IUD expulsion is a risk factor for repeat expulsion, ${ }^{9}$ and Grimes at al. reported that IUD insertions immediately after abortion had a higher expulsion rate than insertions done after a suitable time interval. ${ }^{10}$

Apparently 1 in 5 IUD expulsions are not noticed by the user. ${ }^{45}$ Taking an expulsion rate of $5 \%$, this would give a rate for unnoticed expulsions of $1 \%$. Pregnancy rates for the T-Safe $380 \mathrm{~A}^{\circledR}$ IUD and IUS, respectively, are $1-2 \%$ at 5 years and less than $1 \%$ at 5 years. ${ }^{10}$ It has been calculated that fewer than one-third of all these IUD-related pregnancies follow unnoticed expulsion. ${ }^{11}$ Therefore, taking a failure rate of $1 \%$, perfect concordance with the currently recommended FSRH advice could be expected to reduce pregnancy rates by about $0.33 \%$. However, as the present study shows, women are not following this advice, and so the expected benefit would be considerably less. While any unplanned pregnancy is undesirable, 'typical use' failure rates for intrauterine contraception compare favourably with other contraceptive methods, even when advice on checking threads is not followed.

One of the benefits claimed for long-acting reversible contraception (LARC) is that you can 'fit and forget'. Requiring that women examine themselves regularly may deter some from choosing IUDs. At a time when we are encouraging women to choose LARC methods we should make these methods as simple, attractive and forgettable as possible. The present study suggests that most women ignore the current advice regarding checking their IUD threads, and this may be because they do not find this advice either useful or easy to follow.

The Association of Reproductive Health Professionals in the USA advises that "women who want reassurance about placement of the IUD can check for presence of the string, although checking on a regular basis is not necessary". ${ }^{12}$ The United States Agency for International Development IUD guidelines state that: "the importance of having the client check her strings has been over-emphasised. IUD expulsion is uncommon, undetected expulsion is rare ... the provider should minimise this aspect of counselling and focus more on other messages". ${ }^{13}$

\section{Study limitations}

The present study is limited to the details around thread checking, and IUD expulsion or pregnancy rates were not investigated. However, these have recently been calculated in a separate study conducted in the authors' department, ${ }^{14}$ and the figures are similar to the published data quoted above. The authors did not set out to calculate the impact on the number of unplanned pregnancies that any change in the advice given to IUD users might bring about. It is also not possible to demonstrate how many more women might choose this contraceptive method if they did not feel that regular selfexamination is required.

In asking how comfortable the IUD/IUS users felt about self-examination it should be remembered that this is already a self-selected group of women who have chosen to use these methods, including accepting the current advice on thread-checking. There may be a significant number of women who have not chosen this method perhaps because they do not want to selfexamine, and hence they were not included in the study.

Similarly, the present study only included those women who were visiting the clinic. It could be that those women who don't attend clinic are more likely 
to forget about their device, and are therefore even less likely to be checking their threads.

The interviewer is a clinic doctor, and therefore the potential for bias in the women's responses needs to be considered. However, it could be argued that the IUD users would be more likely to over-report the frequency of thread-checking so as to appear to be complying with the advice they have been given. This would suggest that the high proportion of women who don't follow the clinic's advice could actually be even higher.

This study did not address the advantages and disadvantages of the routine post-insertion check, which is designed to pick up immediate complications such as infection or perforation.

\section{CONCLUSIONS}

We have shown that most women do not follow the current advice to regularly check their IUD threads. If they did, we predict that this would have huge workload implications for little benefit.

We suggest adopting the approach that unless women are at an increased risk of expulsion then threadchecking should be done for reassurance only. An alternative approach would be to inform the IUD/IUS user of the $1 \%$ chance of unnoticed expulsion, and that only one-third of the $1 \%$ failure rate (i.e. 1 in 300 ) is due to unnoticed expulsion, and let the individual woman decide whether to check for her threads.

In view of the high proportion of women who cannot manage to feel their threads, those users who want to check for their threads, and those who are considered to be at an increased risk of expulsion, should be actively shown how to do it.

Competing interests None.

Ethics approval The study was deemed not to require ethical approved by the authors' local ethics board.

Provenance and peer review Not commissioned; externally peer reviewed.

\section{REFERENCES}

1 National Institute for Health and Clinical Excellence (NICE). Long-acting Reversible Contraception: The Effective and Appropriate Use of Long-acting Reversible Contraception. 2005.
http://www.nice.org.uk/pdf/CG030fullguideline.pdf [accessed 31 October 2012].

2 Faculty of Sexual and Reproductive Health Care Clinical Effectiveness Unit. Intrauterine Contraception. 2007. http:// www.fsrh.org/pdfs/CEUGuidanceIntrauterineContraception Nov07.pdf [accessed 31 October 2012].

3 Tietze C. Evaluation of intrauterine devices: ninth progress report of the Cooperative Statistical Program. Stud Fam Plann 1970;1:1-40.

4 Hernández Valencia M, Becerril Flores LC. Use of modified intrauterine device (IUD) TCu 380 with chromium filaments in the immediate postpartum [in Spanish]. Ginecol Obstet Mex $2000 ; 68: 70-76$.

5 Clinical Effectiveness Unit. FFPRHC Guidance (January 2004). The copper device as long-term contraception. J Fam Plann Reprod Health Care 2004;30:29-42.

6 Husemeyer RP, Gordon H. Retrieval of missing IUCD threads. Br J Sex Med 1980;7:32-34, 51.

7 Marchi NM, Castro S, Hidalgo MM, et al. Management of missing strings in users of intrauterine contraceptives. Contraception 2012;86:354-358.

8 Barsaul M, Sharma N, Sangwan K. 324 cases of misplaced IUCD - a 5-year study. Trop Doct 2003;33: $11-12$.

9 Thonneau P, Almont T, de La Rochebrochard E, et al. Risk factors for IUD failure: results of a large multicentre casecontrol study. Hum Reprod 2006;21:2612-2616.

10 Grimes DA, Lopez LM, Manion C, et al. Cochrane systematic reviews of IUD trials: lessons learned. Contraception 2007;75(Suppl. 6):S55-S59.

11 Population Information Program. IUD - update on safety, effectiveness and research (Series B, No. 3). Popul Rep [B] 1979:B50-B100.

12 Association of Reproductive Health Professionals. Choosing a Birth Control Method: A Quick Reference Guide for Clinicians. 2011. http://www.arhp.org/publications-and-resources/quickreference-guide-for-clinicians/choosing [accessed 11 October 2012].

13 United States Agency for International Development. IUD Guidelines for Family Planning Service Programs: A Problem Solving Reference Manual. 2006. http://www.k4health.org/ toolkits/iud/iud-guidelines-family-planning-service-programsproblem-solving-reference-manual [accessed 11 October 2012].

14 Cook L, Fleming C. What is the actual cost of providing the intrauterine system for contraception in a UK community sexual and reproductive health setting? J Fam Plann Reprod Health Care 2014;40:46-53. 